\title{
Autoindicação do bullying frente as crenças do abuso sexual
}

\section{Self-Indication of bullying against beliefs of sexual abuse}

\section{Autoindicación de acoso a la luz de creencias de abuso sexual}

\section{Thiago de Oliveira Felizmino ${ }^{1}$ (D) Joilson Pereira da Silva² (1)}

${ }^{1}$ Autor para correspondência. Universidade Federal de Sergipe (Aracaju). Sergipe, Brasil. thiagofelizmino@gmail.com ²Universidade Federal de Sergipe (Aracaju). Sergipe, Brasil. joilsonp@hotmail.com

RESUMO | OBJETIVO: Identificar as crenças que os estudantes têm frente ao abuso sexual infantojuvenil. Bem como, verificar se estas interferem na autoindicação do bullying (acariciar sem permissão), tanto entre os provocadores quanto entre os provocados. Para tanto, foram aplicadas: Escala B e ECAS em 284 estudantes de escolas públicas da Grande Aracaju. A análise dos dados se deu por meio do SPSS, versão 25. RESULTADOS: Os resultados demonstraram que a maioria dos participantes discordou das afirmativas contidas na ECAS. Assim como, revelaram que no tocante à prática deste tipo de bullying, destacou-se no sexo feminino, tanto como provocadoras, quanto como provocadas, e que entre os provocados percebeu-se maior concordância com crenças que validam/legitimam o abuso sexual. CONCLUSÃo: Visando ampliar as discussões sobre essa temática, fica a indicação de novos estudos com professores, a fim de vislumbrar seus entendimentos, sentimentos e posturas frente aos casos de abuso sexual entre seus alunos.

PALAVRAS-CHAVE: Bullying, Abuso Sexual, Adolescentes.

ABSTRACT | OBJECTIVE: To identify the beliefs that students have regarding child sexual abuse. As well as check if these interfere with the self-indication of bullying (stroking without permission), both among bullies and among those provoked. For this purpose, Scale B and ECAS were applied to 284 students from public schools in Grande Aracaju. Data analysis was performed using SPSS, version 25. RESULTS: The results showed that most participants disagreed with the statements contained in the ECAS. They also revealed that regarding the practice of this type of bullying, it stood out in females, both as provocateurs and as provoked, and that among the provoked, there was a greater agreement with beliefs that validate/legitimize sexual abuse. CONCLUSION: Aiming to broaden the discussions on this theme, further studies with teachers are indicated to glimpse their understandings, feelings, and attitudes towards cases of sexual abuse among their students.

KEYWORDS: Bullying, Sexual Abuse, Adolescents.

RESUMEN | OBJETIVO: Identificar las creencias que tienen los estudiantes con respecto al abuso sexual infantil. Además, verifique si estos interfieren con la autoindicación de bullying (caricias sin permiso), tanto entre los acosadores como entre los provocados. Para ello, se aplicó la Escala B y ECAS a 284 estudiantes de escuelas públicas de Grande Aracaju. El análisis de datos se realizó utilizando SPSS, versión 25. RESULTADOS: Los resultados mostraron que la mayoría de los participantes no estaban de acuerdo con las declaraciones contenidas en el ECAS. Asimismo, revelaron que, en cuanto a la práctica de este tipo de acoso, se destacó en las mujeres, tanto como provocadoras como provocadas, y que entre los provocados hubo mayor acuerdo con las creencias que validan / legitiman el abuso sexual. CoNCLUSı́́N: Con el objetivo de ampliar las discusiones sobre este tema, se indican estudios adicionales con los docentes, con el fin de vislumbrar sus entendimientos, sentimientos y actitudes hacia los casos de abuso sexual entre sus estudiantes.

PALABRAS CLAVE: Bullying, Abuso Sexual, Adolescentes. 


\section{Introdução}

$\mathrm{Na}$ adolescência, fase do desenvolvimento humano entre a infância e adultez, os indivíduos encontram-se susceptíveis a situações de violência, mesmo ainda que silenciosas ou camufladas (World Health Organization [WHO], 2006; United Nations Children's Fund [UNICEF], 2006). Neste sentido, pesquisa realizada com adultos que foram vítimas de violência na infância ou adolescência, principalmente agressão física no âmbito familiar, constatou que estes tiveram seis vezes mais chances de serem violentados sexualmente ou serem alvo de bullying, em algum momento de suas vidas (Malta et al., 2019).

Uma das formas de violência em que os adolescentes são vítimas constantes é a violência sexual (Alves \& Leal, 2012). A legislação brasileira vigente subdivide a violência sexual contra crianças e adolescente em abuso sexual e a exploração sexual, sendo que a principal diferença entre ambos é que no contexto da exploração sexual envolve transação comercial (Landini, 2011).

Entretanto, o foco nesse estudo foi o abuso sexual em adolescentes. Destarte, o abuso sexual é um fenômeno complexo, pois perpassa por aspectos que vão além da sexualidade, a saber, "abuso de poder" que é exercido pelo grande (forte) sobre um pequeno (fraco), "abuso da confiança" que o pequeno (dependente) deposita no maior (protetor), e "uso delinquente da sexualidade de alguém", que neste caso, está fora da idade de consentimento (Gabel, 2007; Landini, 2011).

Convém ressaltar que o abuso sexual pode vir a ser perpetrado com contato físico (atentado violento ao pudor, estupro, corrupção de menores e violência sexual mediante fraude) e sem o contato físico (assédio sexual, abuso sexual verbal, exibicionismo, voyeurismo) (Associação Brasileira Multiprofissional de Proteção à Infância e Adolescência [ABRAPIA], 1997; Brino \& Willams, 2009; Habigzang \& Caminha, 2004; Landini, 2011; Sanderson, 2005). O abuso sexual pode ser manifestado na forma de bullying, em alguma de suas variações: "direto e físico" - abuso sexual com contato físico, "direto e verbal" - abuso sexual verbal, ou "indireto" - fofocas, boatos, ameaças e o cyberbullying com conotação sexual (Antunes \& Zuin, 2008; Landini, 2011).
Pesquisa sobre bullying e abuso sexual da Universidade de Illinois, nos Estados Unidos, com 1.162 estudantes do ensino médio, revelou que os garotos são mais autores de bullying que as garotas, no tocante às questões que envolvem a sexualidade (37\% garotos e $28 \%$ garotas). O tipo mais comum de bullying relatado foi o tipo direto e verbal, ou seja, agressões verbais, assédio sexual e abuso emocional verbal entre namorados. $73 \%$ das garotas versus $66 \%$ dos garotos afirmaram ter sofrido algum tipo de agressão verbal de cunho sexual (Espelage et al., 2014).

No tocante a realidade brasileira, Pesquisa realizada com estudantes que relataram ter sido vítimas de violências sexuais, concluiu que estes foram mais propensos a utilizarem drogas, álcool e ter amigos que fazem o mesmo. Entretanto, o dado que merece destaque é que estes apresentam, aproximadamente, duas vezes mais chances de já terem sido alvo de bullying. E com isso, mais chances de defasagem idade-série e baixo entusiasmo de avançar nos estudos, devido a dois possíveis fatores: busca por se livrar do bullying e receio que mais pessoas saibam acerca do abuso sexual sofrido (Fontes et al., 2017).

Para além dessas questões, o abuso sexual desencadeia outros efeitos que perpassam pelos âmbitos físico e mental, em curto, médio e longo prazo. No que diz respeito às consequências físicas imediatas estão às agressões a integridade física, gravidez não planejada (em relação às mulheres) e infecções sexualmente transmissíveis (ISTs). Quanto aos prejuízos mentais, está a vulnerabilidade para o aparecimento de sintomas e transtornos psiquiátricos, a saber, transtorno de estresse pós-traumático, transtorno depressivo, transtorno de pânico, somatização, tentativa de suicídio, abuso e dependência de substâncias psicoativas, etc. (Facuri et al., 2013).

Uma das formas de investir no enfrentamento é analisar as crenças sobre a natureza do abuso sexual contra crianças e adolescentes. Pois as crenças sobre grupos sociais funcionam como princípios organizadores que motivam os comportamentos e as atitudes. Neste sentido, para fins de definição, crenças são uma representação aceita por uma ou mais pessoas, atuando de forma direta nas atitudes e comportamentos humanos, agindo na socialização e formação cultural e ideológica da sociedade, em outras palavras, as crenças orientam as condutas sociais e influenciam as 
tomadas de decisões (Camino et al., 2013; Maciel et al., 2015; Pereira et al., 2019; Salgado, 2012).

Desse modo, o presente artigo objetiva identificar as crenças que os estudantes têm frente ao abuso sexual infanto-juvenil, bem como verificar se tais crenças interferem na autoindicação do bullying (do tipo acariciar sem permissão), tanto entre os provocadores quanto entre os provocados.

\section{Método}

\section{Participantes}

Tratou-se de uma amostra de conveniência, não probabilística, composta por 284 participantes, seguindo os seguintes critérios: de inclusão: estudantes de ambos os sexos, matriculados no $9^{\circ}$ ano do Ensino Fundamental em escolas públicas da Grande Aracaju, Estado de Sergipe $(n=8)$, devidamente autorizados a participarem da pesquisa por seus responsáveis; de exclusão: estudantes de outros Anos, de escolas particulares e sem a permissão de suas participações. A idade dos participantes apresenta variância entre 14 a 18 anos, sendo que a maioria era do sexo feminino ( $\mathrm{n}$ $=174 ; 61,3 \%)$, com média de idade de 15,4 anos (DP = $1,15)$, os quais informaram possuir alguma religião $(n=$ $214 ; 75,4 \%)$ e não possuir alguma deficiência $(n=279$; 98,2\%). Em relação a raça/etnia, maior parte identificou-se como pardo ( $n=140 ; 49,3 \%)$ e estudam desde o ano de 2015 na escola em que foi realizada a pesquisa ( $n=79 ; 27,8 \%$ ). Concernente ao grau de instrução do(a) chefe familiar, a maioria não possui o Ensino Médio completo ( $n=148 ; 52,1 \%$ ). No quesito raças/ etnias, poucos se consideram indígena $(n=1 ; 0,4 \%)$ ou amarelo $(n=4 ; 1,4 \%)$, tendo a maioria parda $(n=140$; $49,3 \%)$, seguida de preto $(n=63 ; 22,2 \%)$ e branco ( $n$ $=43 ; 15,1 \%)$. Ressalta-se que parte dos participantes deste estudo não identificaram a sua raça/etnia $(n=$ 33; $11,6 \%)$.

\section{Instrumentos}

\section{Questionário de dados pessoais do aluno}

Por meio deste instrumento, foram coletados dados pessoais dos alunos, tais como sexo, idade, religião, tempo em que está na escola atual. Sendo que por meio da escolaridade da pessoa que é a considerada chefe da família do aluno e os bens que possui em sua casa, avaliou-se seu nível socioeconômico em conformidade com o instrumento Critério de Classificação Econômico Brasil, elaborado pela Associação de Anunciantes (ABA-ABIPEME).

\section{Escala de Autoindicação de Bullying (Escala B)}

Elaborada para obter os dados referentes a auto-observação do bullying, como procederam e Roth et al. (2010), Salmivalli et al. (2011) e Hein et al. (2015), nesta escala os participantes respondem a dois quadros, os quais apresentam diferentes tipos de agressões. Estas agressões são divididas em dois grupos, um que quanto às agressões cometidas contra os colegas, e outro, quanto as possíveis agressões sofridas. Dentre as agressões estão os questionamentos "Os acariciou contra sua vontade?" e "Acariciaram você contra sua vontade?", que denotam um subtipo do abuso sexual na forma de bullying. Para responder, cinco alternativas são apresentadas, indicando a frequência em que a agressão foi cometida e/ou sofrida.

\section{Escala de Crenças Sobre Abuso Sexual (ECAS)}

Esta escala foi desenvolvida por Machado et al. (2000), em Portugal, adaptada e validada para o contexto brasileiro por Pereira et al. (2019). Originalmente, é constituída por 17 itens, cujas opções de resposta encontram-se formuladas numa escala de Likert de 5 pontos, correspondendo desde 1 ("discordo totalmente") a 5 ("concordo totalmente"). Sendo, posteriormente, determinados três fatores: a) legitimação do abuso pela sedução infantil (itens 4, 6, 8, 9, 11, 12, 13 e 16); b) a sua legitimação pela ausência de violência (itens 7, 9, 10, 11, 13, 14, 15 e 17); e c) a crença de que o abuso não existe quando o ofensor não corresponde a um estereótipo pré-definido (itens 1, 2, 3, 4 e 5). Pereira et al. (2019) propuseram uma mudança com relação à estrutura fatorial, sendo proposta a unifatorialidade da escala e a retirada de 06 itens que foram os de número 1, 2, 3, 4, 8 e 9, ficando a escala final com 11 itens. Entretanto, convém reiterar que neste estudo os 17 itens foram utilizados, e outros três fatores foram encontrados, a saber, a) legitimação do abuso pela sedução infanto-juvenil e pela ausência de violência (itens 13, 12, 6, 14, 7, 11 e 10); b) legitimação pela normalidade do abuso e do abusador (itens 16, 5, 9, 15, 8 e 17); c) legitimação do abuso por 
não compreendê-lo como violência (itens 2, 1, 4 e 3). O índice total do questionário constitui uma medida genérica de tolerância/legitimação do abuso sexual, que permitem avaliar as crenças centrais subjacentes a tal legitimação.

\section{Procedimentos de coletas de dados}

\section{Cuidados éticos}

O presente estudo é um dos desdobramentos do projeto de pesquisa intitulado "Bullying e abuso sexual: um estudo a partir das representações sociais de professores e estudantes de escola pública de Aracaju", que foi submetido ao Comitê de Ética, por meio da Plataforma Brasil com o Certificado de Apresentação para Apreciação Ética (CAAE) 92396718.0.0000.5546, durante o mestrado em Psicologia pela Universidade Federal de Sergipe, sendo devidamente aprovado sob o parecer de número 2.897.758.

Na sequência, foi protocolado um ofício, no dia 19/04/2018, à Diretoria de Educação de Aracaju (DEA), órgão ligado à Secretaria de Estado da Educação de Sergipe (SEDUC), apresentando o referido projeto e solicitando a autorização de sua aplicação nas escolas estaduais, que, após as análises, foi devidamente assinada a anuência, no dia 13/06/2018, sendo, posteriormente, selecionadas oito escolas da Grande Aracaju.

Nos meses de agosto e setembro de 2018 , em dias previamente agendados, foram entregues os Termos de Consentimento Livre e Esclarecido (TCLE) para os participantes maiores de idade. De igual modo, os Termos de Assentimento Livre e Esclarecido (TALE) foram encaminhados, pelos próprios alunos menores de 18 anos, para seus responsáveis, a fim de que autorizassem suas participações. Na oportunidade, foi esclarecido o objetivo da pesquisa, ao tempo em que foram dirimidas as dúvidas existentes, e em seguida realizada a coleta dos dados.

\section{Procedimento de Análise dos Dados}

Os dados foram tabulados e analisados por meio do Pacote Estatístico para Ciências Sociais (SPSS) para Windows versão 25.0. Realizaram-se análises fatoriais exploratórias por intermédio do método dos componentes principais com o intuito de conhecer a estrutura fatorial da ECAS. Utilizou-se também o alfa de Cronbach (a de Cronbach) para verificação da consistência interna da mesma. Assim como também outras análises descritivas e cruzamentos com a Escala B.

\section{Resultados e discussões}

\section{Análise dos Resultados Agregados}

Nesse estudo optou-se por apresentar os resultados e suas respectivas discussões na mesma seção. Neste sentido, mediante as análises empregadas, percebeu-se que as opções "discordo totalmente" e "discordo" foram as mais escolhidas, ambas corresponderam a $77,2 \%$. Outro ponto que chamou atenção foi o fato de que $14,6 \%$ das respostas foram em direção a não concordarem e nem discordarem, a qual demonstra a preferência pela linha da neutralidade. Enquanto que ao somar "concordo" e "concordo totalmente", chegou-se a 8,2\% das respostas, conforme expresso no Gráfico 1.

Gráfico 1. Resultados agregados

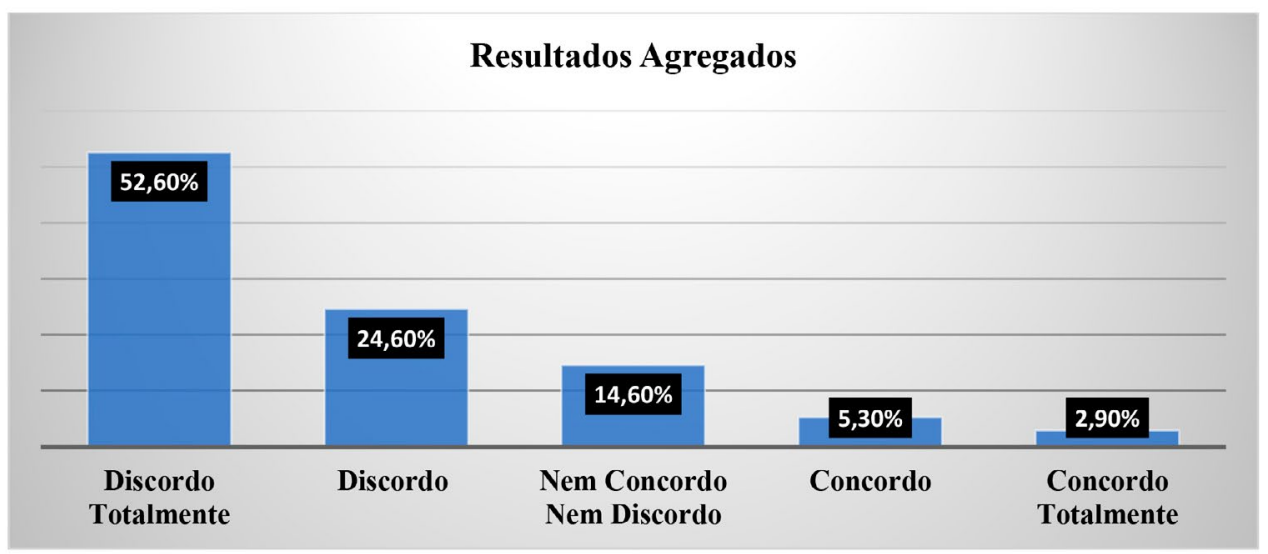


Estes dados demonstram que a grande maioria dos participantes possui crenças que não validam e nem legitimam o abuso sexual. Evidenciando uma alteração de consciência social acerca deste fenômeno, assim como ressaltou Almeida (2003) ao afirmar, em seus estudos, que houve uma evolução ao longo dos tempos no que diz respeito às concepções das vicissitudes envolvendo as violências sexuais. Pois o que se percebe é a saída de posições mais culpabilizantes da vítima, para outras mais conscientes da dimensão e da severidade do fenômeno.

Em parte, um grande responsável para essa evolução social é o enquadramento legal/jurídico que é dado a esse tipo de comportamento criminoso, e as discussões sociais na procura de uma definição técnica coerente do abuso sexual de crianças e adolescentes (Almeida, 2003). Pois, para além das questões voltadas para o endosso (ou não) de crenças deste tipo, o foco principal deve ser, a priori, voltado para a investigação e punição das atitudes violentas cometidas, neste caso, o abuso sexual (Moyano et al., 2016).

\section{Análise Fatorial}

Por conseguinte, procurou-se comprovar a fatorabilidade da matriz de correlações entre os itens da escala; os resultados apoiaram a adequação de se utilizar uma análise fatorial exploratória, observando os seguintes índices que se mostraram adequados: $\mathrm{KMO}=0,878$ e o Teste de Esfericidade de Bartlett, $\lambda 2(136)=1310,307 ; \mathrm{p}<0,001$, que explicam $45,965 \%$ da variância total. A fim de verificar a consistência interna da escala, utilizou-se também o alfa de Cronbach, cujo valor encontrado foi 0,858, considerado satisfatório (Bland \& Altman, 1997).

Tabela 1. Estrutura Fatorial da ECAS

\begin{tabular}{|c|c|c|c|c|}
\hline \multirow{2}{*}{ Nome do Fator } & \multirow{2}{*}{ Item da ECAS } & \multicolumn{3}{|c|}{ Carga Fatorial } \\
\hline & & Fator 1 & Fator 2 & Fator 3 \\
\hline \multirow{7}{*}{$\begin{array}{l}\text { Legitimação do abuso pela } \\
\text { sedução infanto-juvenil e } \\
\text { pela ausência de violência. }\end{array}$} & $\begin{array}{l}\text { 13. Só com crianças pequenas é que se pode } \\
\text { falar de abuso. Se um(a) adolescente se } \\
\text { envolve com alguém mais velho, a culpa é } \\
\text { sua. }\end{array}$ & 0,780 & 0,098 & $-0,038$ \\
\hline & $\begin{array}{l}\text { 12. As adolescentes levam os homens mais } \\
\text { velhos a abusar delas. }\end{array}$ & 0,677 & 0,238 & 0,140 \\
\hline & $\begin{array}{l}\text { 6. As crianças podem provocar o abuso pelo } \\
\text { seu comportamento sedutor. }\end{array}$ & 0,668 & 0,028 & 0,354 \\
\hline & $\begin{array}{l}\text { 14. Se o abusador não tiver magoado a } \\
\text { criança/adolescente o abuso é pouco grave. }\end{array}$ & 0,571 & 0,301 & 0,292 \\
\hline & $\begin{array}{l}\text { 7. Só se pode falar de abuso quando há } \\
\text { violência. }\end{array}$ & 0,532 & 0,325 & 0,156 \\
\hline & $\begin{array}{l}\text { 11. Se uma criança/adolescente só se queixa } \\
\text { do abuso muito mais tarde, então ele } \\
\text { provavelmente não existiu. }\end{array}$ & 0,522 & 0,254 & 0,260 \\
\hline & $\begin{array}{l}\text { 10. Se alguém abusa sexualmente de uma } \\
\text { criança/adolescente, é porque não consegue } \\
\text { arranjar parceiras(os) adultas(os). }\end{array}$ & 0,414 & 0,189 & 0,362 \\
\hline \multirow{6}{*}{$\begin{array}{l}\text { Legitimação pela } \\
\text { normalidade do abuso e do } \\
\text { abusador. }\end{array}$} & $\begin{array}{l}\text { 16. A maioria das queixas de abuso sexual são } \\
\text { falsas. }\end{array}$ & 0,200 & 0,676 & 0,208 \\
\hline & $\begin{array}{l}\text { 5. Os abusadores são pessoas que parecem } \\
\text { diferentes das pessoas normais. }\end{array}$ & 0,079 & 0,575 & 0,140 \\
\hline & $\begin{array}{l}\text { 9. Se uma menina já foi abusada antes, então } \\
\text { é natural que outros homens também } \\
\text { abusem ela. }\end{array}$ & 0,091 & 0,565 & 0,067 \\
\hline & $\begin{array}{l}\text { 15. Só se pode falar de abuso se a } \\
\text { criança/adolescente resistir fisicamente. }\end{array}$ & 0,439 & 0,561 & $-0,040$ \\
\hline & $\begin{array}{l}\text { 8. A maioria das queixas de abuso sexual são } \\
\text { inventadas pelas mães (por exemplo: nos } \\
\text { processos de divórcio). }\end{array}$ & 0,315 & 0,527 & 0,052 \\
\hline & $\begin{array}{l}\text { 17. Se não houver penetração, então o abuso } \\
\text { é pouco grave. }\end{array}$ & 0,468 & 0,497 & 0,179 \\
\hline \multirow{4}{*}{$\begin{array}{l}\text { Legitimação do abuso por } \\
\text { não o compreender como } \\
\text { violência. }\end{array}$} & 2. Só as meninas são vítimas de abuso sexual. & 0,177 & 0,014 & 0,745 \\
\hline & $\begin{array}{l}\text { 1. É muito raro uma criança/adolescente ser } \\
\text { abusada sexualmente. }\end{array}$ & 0,221 & $-0,021$ & 0,629 \\
\hline & $\begin{array}{l}\text { 4. A maioria das queixas de abuso sexual são } \\
\text { fantasias da criança/adolescente. }\end{array}$ & 0,183 & 0,313 & 0,531 \\
\hline & $\begin{array}{l}\text { 3. As pessoas que abusam sexualmente de } \\
\text { criança/adolescente são quase sempre } \\
\text { desconhecidas. }\end{array}$ & $-0,033$ & 0,302 & 0,529 \\
\hline
\end{tabular}


A partir da análise fatorial (Tabela 1), observou-se haver certa semelhança com a pesquisa realizada por Ladeiro (2014), em que também foram extraídos três fatores da ECAS, e diante de tal semelhança, optouse por utilizar nomenclaturas semelhantes, a saber, "legitimação do abuso pela sedução infanto-juvenil e pela ausência de violência", "legitimação pela normalidade do abuso e do abusador" e "legitimação do abuso por não compreendê-lo como violência".

No primeiro fator, sua precisão, avaliada por meio do Coeficiente Alfa de Cronbach, foi considerada substancial $(a=0,80)$. Em todos os itens que compõem este fator, prevaleceu o índice de discordância (somando as opções discordo e discordo totalmente), a saber, 13 (74\%), 12 (77,8\%), 6 (68\%), 14 (88,8\%), 7 (84,9\%), $11(82 \%)$ e $10 "(70,8 \%)$.

No sentido oposto, mesmo que em menor número, os adolescentes que concordaram totalmente ou apenas concordaram com os itens deste fator, denotaram acreditar que o abuso sexual pode acontecer em razão da manifestação de determinados comportamentos sedutores nas crianças e/ou nos adolescentes. Com esse tipo de crença, de modo implícito, tenderam a minimizar a responsabilidade do abusador.

Autores explicam que o surgimento e fortalecimento destes tipos de crenças se devem ao fato de que alguns adultos, principalmente, os perpetradores de abuso sexual, compreendem os comportamentos de ternura (sentar no colo, acariciar, beijar, determinadas posições corporais nas brincadeiras) como comportamentos de sedução (Ferenczi, 2011; Mendes \& França, 2012; Silva \& Inada, 2013). Em contrapartida, se estes tipos de comportamentos são presenciados de fato nas crianças/adolescentes, não devem ser desprezados, pois podem ser indícios e até mesmo sintomas de alguém que sofreu ou vem sofrendo abuso sexual (Florentino, 2015).

Ainda de acordo com as crenças contidas neste fator, o abuso não passa a ser considerado algo tão grave se não houver a comprovação de violência física; que os subtipos de abusos sexuais sem contatos físicos, e/ou aqueles sem o emprego de força que deixem marcas visíveis no corpo, são compreendidos como menos prejudiciais. Machado et al. (2000), em seus estudos, constataram que é frequente esse tipo de crença, que ameniza o abuso quando não é perpetrado sob violência física. Contudo, tratam-se de crenças totalmente refutadas pela legislação brasileira vigente, a saber, Constituição Federal de 1988, Estatuto da Criança e do Adolescente (ECA) e Código Penal, e por pesquisas científicas que comprovaram que o abuso sexual, independentemente do tipo, sempre causa consequências em algum nível, para as vítimas (Florentino, 2015; Landini, 2011).

O segundo fator foi composto por 6 itens, da qual o Coeficiente Alfa Cronbach foi considerado substancial $(a=0,71)$. Nestes itens também prevaleceu o índice de discordância (somando as opções discordo totalmente e apenas discordo): 16 (78,6\%), 5 (57,1\%), 9 (88\%), 15 $(81,4 \%), 8$ (72,6\%) e $17(88,4 \%)$. No tocante aos índices de concordância com esses mesmos itens, o entendimento que se faz é que, para quem respondeu, o abuso sexual tornou-se algo corriqueiro no cenário atual, ou seja, um assunto recorrente nos noticiários e nas conversas informais no próprio bairro.

A junção entre os dados estatísticos que comprovam que a violência sexual, de modo geral, na infância e adolescência é algo frequente tanto no Brasil quanto no mundo (Guedes et al., 2016; Matos et al., 2018), com uma comunicação sistematicamente distorcida, aliada com a impunidade sutilmente legitimada, tendem a normalizar (Accorssi et al., 2012) o abuso na sociedade.

As crenças legitimadas pela normalidade do abusador fazem com que o perpetrador de abuso sexual seja visto como um indivíduo desajustado socialmente e/ou com desordem mental (Machado et al., 2000). Entretanto, essa não é a única razão para que os abusos aconteçam, pois a maioria dos casos estudados revelaram motivações variadas, e que raramente tiveram origem em transtornos mentais graves ou em parafilias (Serafim et al., 2009). 
Como também confirmaram que não há relação direta com a uma faixa etária específica, visto que em torno de $30 \%$ dos casos de abuso sexual no mundo são praticados por menores de 18 anos (Costa et al., 2011; Moyano et al., 2016; Sanderson, 2005; Wolff et al., 2016). Assim como não se comprovou relação com um único gênero, pois até mesmo entre adolescentes, há perpetradores de ambos os sexos. No caso do sexo feminino, geralmente, acontece quando estão em situações de responsabilidade, como babás, por exemplo (Pincolini \& Hutz, 2014).

A grande maioria dos autores são pessoas do sexo masculino (Platt et al., 2018). Ainda quando adolescentes, principalmente, são irmãos, meios-irmãos ou primos (Pincolini \& Hutz, 2014). Quando adultos, geralmente, são pessoas da própria família, conhecidos próximos ou figuras de responsabilidade. Atuam sozinhos e se utilizam da própria casa da vítima ou de um outro local na circunvizinhança. $O$ abuso raramente é perpetrado uma única vez, podendo durar por anos (Landini, 2011).

No terceiro fator, o Coeficiente Alpha de Cronbach foi considerado moderado $(a=0,56)$, e como nos dois fatores anteriores, percebeu-se elevados índices de discordância nos itens: 2 (85,9\%); 1 (83,5\%); 4 (77,4\%) e $3(54,2 \%)$. No sentido oposto, concordar com estes itens indica a existência de crenças de que o abuso sexual, na maioria dos casos, não é uma violência considerada grave.

Pensar assim é acreditar que os relatos são insinuações fantasiosas por parte das vítimas; portanto, não merecedoras do devido crédito. Quanto a isso, Denov (2003) esclareceu que quando as denúncias de abuso das vítimas não são levadas à sério, parecem exacerbar os efeitos negativos do abuso e incitam à médio e longo prazo, a vitimação secundária. Crença desse tipo vai na contramão da realidade atual, pois estima-se que no mundo todo, anualmente, cerca de 40 milhões de crianças e adolescentes sofram abuso sexual (Santos et al., 2018).

Estes dados também revelaram que esse tipo de crença é ressaltado quando a vítima denunciante é do sexo masculino. Na contramão de tais crenças, crianças ou adolescentes do sexo masculino também são vítimas desse tipo de abuso sexual. Este fato foi evidenciado em pesquisa, realizada a partir de notificações sistemáticas, ao demonstrar que mesmo em menor proporção em comparado ao quantitativo de vítimas do sexo feminino, no tocante à recorrência do abuso, em Florianópolis, foi mais frequente, justamente, nas vítimas do sexo masculino (Platt et al., 2018).

\section{Análise dos Escores}

O índice total da ECAS corresponde a uma medida genérica de tolerância/legitimação do abuso sexual infanto-juvenil. Logo, quanto mais altos os escores, maior indicativo de tolerância/legitimação (Pereira et al., 2019). Partindo desse pressuposto, o Gráfico 2 mostra que nenhum estudante pontuou o escore máximo (85).

Apenas um participante pontuou o escore 64, sendo este o indivíduo que mais manifestou crenças de tolerância/legitimação do abuso sexual. 11 estudantes pontuaram o menor escore (17), correspondendo $3,9 \%$ dos participantes. Os escores totais foram bastante diversificados; todavia, 18 estudantes $(6,3 \%)$ pontuaram 24, sendo este o escore de maior coincidência. Pode-se perceber, também, que quanto maior foi o escore total, menor é o número de participantes. Isto é, o grande volume de participantes está entre o escore 17 e o 40, sendo que do escore 41 ao 64, houve uma tendência decrescente de participantes. 


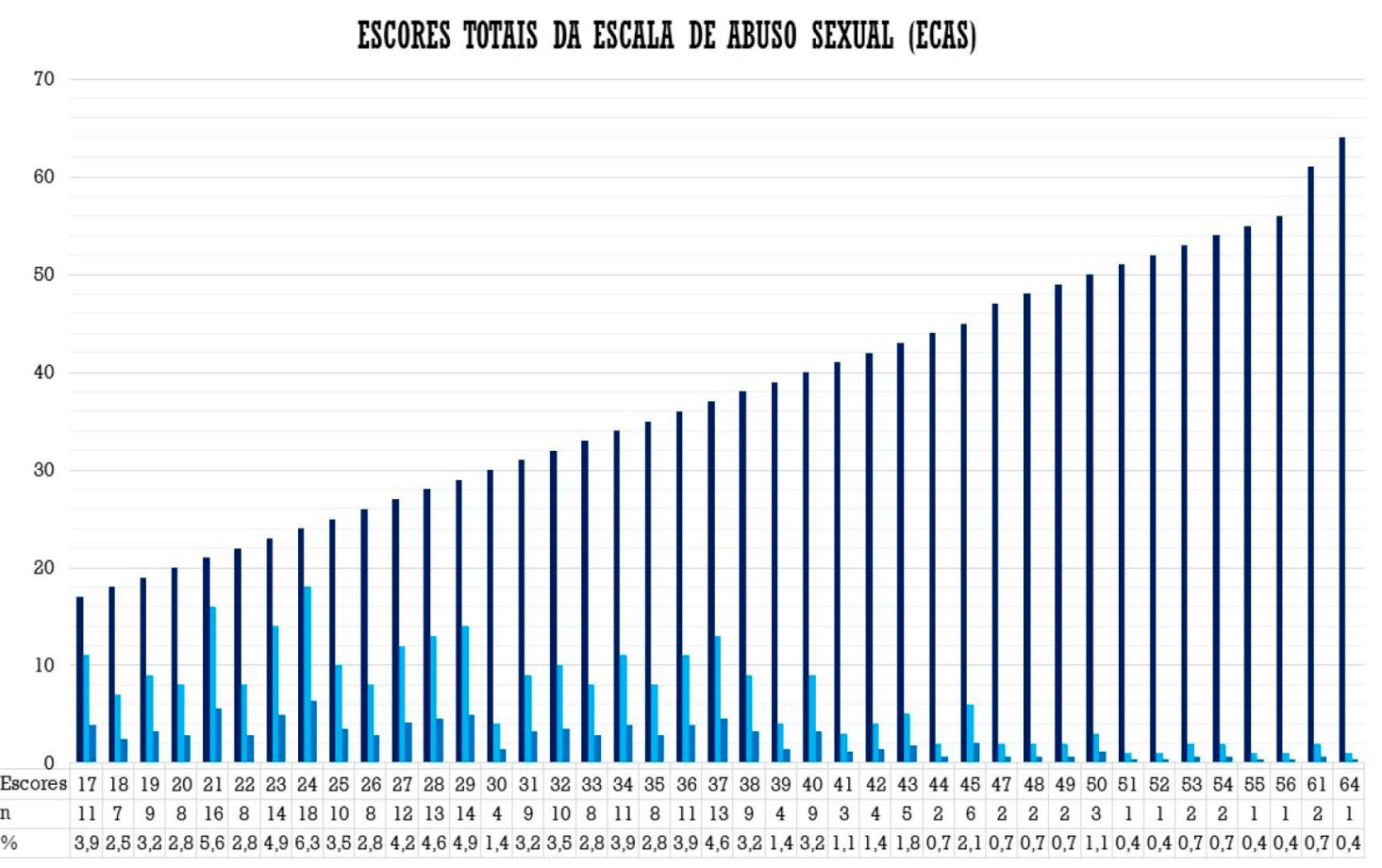

Por meio destes dados, percebeu-se a forma como o abuso sexual infantojuvenil tem sido compreendido pelos adolescentes da Grande Aracaju. O fato da maioria não atingir escores altos, demonstra mudanças nas concepções acerca deste fenômeno. Convém ressaltar que tais mudanças também têm sido evidenciadas nos discursos legais (campo do direito) e técnico (campo das pesquisas científicas). São consideradas evoluções, porque traduzem que o abuso não é algo simples, que não segue uma mesma linha; mas, o resultado de um conjunto de comportamentos e da reação social a estes comportamentos, que, por sua vez, também é mutável (Almeida, 2003).

Implicitamente, através dos escores, os participantes expuseram outras crenças, além daquelas expressas na ECAS: apesar da cena de abuso sexual, há uma história de vida que deve ser considerada (Silva \& Teixeira, 2017); que trata-se de uma das formas mais graves de violência (Marra \& Costa, 2018); que o abusador não pode ficar impune (Azambuja, 2005); que a culpa não é da vítima, como o perpetrador tende a alegar (Pfeiffer \& Salvagni, 2005).

\section{Análise do abuso sexual (acariciar sem permissão) por meio da Escala B}

Por meio da Escala B, foi solicitado que os estudantes informassem a frequência em que vivenciaram determinados tipos de bullying, tanto como provocadores (autores de bullying), quanto provocados (alvos de bullying). Dentre os variados tipos de bullying (indireto, direto-verbal e direto-físico), havia o questionamento "os acariciou contra sua vontade?", para os provocadores, e "acariciaram você contra sua vontade?", para os provocados. Estas eram as opções de respostas: não; uma a duas vezes por semestre; uma a três vezes por mês; uma a quatro vezes por mês; e todos os dias.

Desconsiderando as respostas negativas, percebeu-se por meio da Tabela 2 que os participantes informaram serem provocadores, em algum dado momento, do subtipo de abuso sexual acariciar sem permissão, totalizando de 31 participantes. Destes, 21 (67,7\%) são do sexo feminino e 10 (32,3\%) masculino.

Alguns estudos (Almeida, 2003; Broussard et al., 1991; Denov, 2003) referem que o público em geral percebe o abuso sexual perpetrado por mulheres como sendo menos danoso e menos grave que quando perpetrado por homens. Estas interpretações se dão pelo fato de que os relatos de abuso sexual provocados por mulheres, muitas das vezes, são referidos como sendo "demonstrações de amor mal interpretadas" ou "afetos inapropriados" (Almeida, 2003; Hetherton, 1999). 
Tabela 2. Provocadores (os acariciou contra sua vontade?)

\begin{tabular}{|c|c|c|c|c|}
\hline Opção de Resposta & 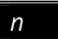 & $\%$ & Feminino & Masculino \\
\hline Não & 253 & 89,1 & 153 & 100 \\
\hline Uma a duas vezes por semestre & 17 & 6,0 & 10 & 7 \\
\hline Uma a três vezes por mês & 5 & 1,8 & 4 & 1 \\
\hline Uma a quatro vezes por mês & 3 & 1,1 & 3 & 0 \\
\hline Todos os dias & 6 & 2,1 & 4 & 2 \\
\hline Total: & 284 & 100,0 & 174 & 110 \\
\hline
\end{tabular}

De igual modo, também desconsiderando as respostas negativas, a Tabela 3 demonstra que dentre tantos outros tipos de bullying, os participantes $(n=58)$ informaram que, em algum momento ou até mesmo todos os dias, foram acariciadas sem dar o consentimento. Dentre os participantes, $38(65,5 \%)$ são do sexo feminino e $20(34,5 \%)$ masculino.

Este tipo de abuso sexual, assim como os outros subtipos são altamente prevalentes em todas as sociedades investigadas, é o que aponta uma metanálise realizada com estudos internacionais. Os números revelaram que entre as crianças e adolescentes, cerca de $20 \%$ (sexo feminino) e $8 \%$ (masculino) em algum momento de suas vidas foram vítimas. Não diferentemente no Brasil, a maioria de casos de abuso sexual ocorrem em meninas entre 5 e 10 anos. Os meninos, por sua vez, também são abusados, porém em menor proporção, principalmente quando o abuso é intrafamiliar (Platt et al., 2018).

Tabela 3. Provocados (acariciaram você contra sua vontade?)

\begin{tabular}{lllll}
\hline \hline Opção de Resposta & $n$ & $\%$ & Feminino & Masculino \\
\hline Não & 226 & 79,6 & 136 & 90 \\
\hline Uma a duas vezes por semestre & 28 & 9,9 & 19 & 9 \\
\hline Uma a três vezes por mês & 8 & 2,8 & 6 & 2 \\
\hline Uma a quatro vezes por mês & 5 & 1,8 & 2 & 3 \\
\hline Todos os dias & 17 & 6,0 & 11 & 6 \\
\hline Total: & 284 & 100,0 & 174 & 110 \\
\hline \hline
\end{tabular}

De todas as respostas, a opção "todo os dias" chamou atenção pelo fato de que o adolescente assume uma constância na pratica do ato de acariciar alguém sem receber o devido consentimento, assim como no caso de quem é acariciado diariamente. Sob esse aspecto, convém ressaltar que a percepção é distinta para os provocadores e provocados. Isto é, apenas 6 participantes provocaram esse tipo de bullying cotidianamente, sendo que destes, 4 $(66,7 \%)$ são do sexo feminino e 2 (33,3\%) masculino. Em contrapartida, o número de estudantes aumenta quando se trata de provocados, 17 estudantes revelaram ser acariciados sem consentir todos os dias, sendo $11(64,7 \%)$ do sexo feminino e $6(35,3 \%)$ masculino.

Apesar dos estudos sobre a dinâmica do assédio sexual comprovarem que, majoritariamente, os homens são os assediadores e as mulheres suas vítimas (Fonseca, Portela et al., 2018; Tsukamoto et al., 2019), pesquisas recentes (Ministério do Trabalho e Emprego, 2013; Fonseca et al., 2018) revelam que qualquer sujeito, independente do gênero e da orientação sexual pode ser assediado, assim como também podem perpetrar o assédio. Tais pesquisas entram em concordância com os resultados deste estudo, em que as garotas se sobressaíram tanto no papel de provocadoras, quanto provocadas.

\section{Cruzamento entre os escores da opção "todos os dias" dos provocadores e provocados com os escores da ECAS}

Ainda tomando por base a opção de resposta "todos os dias" da Escala B, tanto para quem pratica quanto para quem sofre essa violência (acariciar ou ser acariciado sem permissão), pode-se vislumbrar que os provocados ( $\mathrm{n}$ = 17) tenderam a concordar com os itens da ECAS, externalizando crenças que toleram/legitimam o abuso sexual. 
Dos 17 itens presentes na ECAS, dentre aqueles adolescentes que foram provocados todos os dias, percebeu-se mais marcações em opções de concordância (concordo e/ou concordo totalmente), ou seja, em 16 itens: $1(n=2) ; 3(n=5) ; 4(n=1) ; 5(n=5) ; 6(n=$ 2); $7(n=1) ; 8(n=1) ; 9(n=1) ; 10(n=3) ; 11(n=1)$; $12(n=1) ; 13(n=2) ; 14(n=1) ; 15(n=4) ; 16(n=1)$; $17(n=2)$. O item "2" foi único que não seguiu essa tendência. Nesse contexto, três fatores merecem ser contextualizados: a) questão do "consentimento" da vítima; b) a ausência de força física; c) psicoadaptação e habituação.

Em relação à questão do consentimento da vítima, convém ressaltar que na dinâmica do abuso sexual é desencadeado um processo de dominação psicológica do abusador para com a vítima, deixando-a com poucas condições de reação. Devido a isso, a vítima não pode ser responsabilizada pelo que fez enquanto dominada, nem tampouco questionada se deu ou não o consentimento (Faleiros, 2000; Santos \& Dell' Aglio, 2008).

Outra característica do abuso sexual, em especial do tipo "acariciar sem permissão", é a não utilização do uso da força física. Ao contrário, é perpetrado pelo poder exercido, coação e/ou sedução, sem deixar marcas físicas nas vítimas, dificultando a sua identificação (Santos \& Dell' Aglio, 2008). Associado a isso, está a sutileza dos primeiros contatos íntimos, compreendidos, muitas das vezes, como afagos, uma espécie de privilégio, devido a atenção diferenciada que Ihe é ofertada (De Antoni \& Koller, 2002; Pfeiffer \& Salvagni, 2005).

O terceiro fator refere-se aos fenômenos psicológicos que são desencadeados nas vítimas em razão da frequência em que a violência acontece, neste caso, todos os dias. O primeiro trata-se da psicoadaptação, um fenômeno inconsciente que provoca a diminuição do grau de intensidade da satisfação ou do sofrimento devido a exposição ao longo do tempo de um mesmo estímulo (Duarte, 2015). Estar imersos, diuturnamente, no contexto de violência, pode ter levado os provocados ao segundo fenômeno: habituação. Ou seja, entraram no processo de se acostumar com a situação (American Psychological Association [APA], 2010), e desenvolveram crenças que validam/ legitimam o abuso sexual
Diferentemente, aqueles que acariciaram sem permissão todos os dias $(n=6)$ apresentaram concordância em apenas 5 itens, a saber, $3(n=1), 5(n=$ 2), $6(n=2), 11(n=1), 12(n=2)$ e $13(n=1)$. Quanto $a$ isso, duas questões chamaram atenção: a) o fato de 17 adolescentes afirmarem que foram provocadas todos os dias, sendo que apenas 6 afirmaram provocar todos os dias; b) o baixo índice de provocadores externalizando crenças que validam/legitimam o abuso sexual.

A explicação para essas duas questões está no não reconhecimento, por parte dos provocadores, de que acariciar sem o consentimento seja um ato de violência, devido a naturalização desse fenômeno. A naturalização, neste sentido, trata-se do processo mental interpretativo que não produziu a realidade local (neste caso, o ato de acariciar sem permissão todos os dias); mas, o meio pelo qual a interpreta como sendo natural, ao invés de ser vista como um produto social e histórico (Viana, 2013). Em outras palavras, muitos adolescentes não assumiram ser provocadores, por não reconhecer em seus comportamentos algo que seja fora do considerado "normal".

\section{Considerações finais}

Após análise dos resultados, ficou evidenciado que o abuso sexual (do tipo acariciar sem permissão) é um fenômeno presente no cotidiano das escolas onde este estudo foi realizado. Acredita-se que, em alguns casos, esse tipo de violência de cunho sexual possa ser uma manifestação do bullying escolar, haja vista que para ser considerado bullying, se faz necessário estar embutida a relação de poder, haver intencionalidade e frequência dos atos, que foram, sistematicamente, verificados nesse estudo. Destarte, convém reiterar que por mais sutil que essa prática possa ser compreendida por algumas pessoas, trata-se de uma problemática bem atual e que deixa dolorosas consequências nas vítimas (Facuri et al., 2013).

Apesar da existência de discussões sociais e políticas de enfretamento, percebe-se que ainda não foi o suficiente para libertar a temática do abuso sexual das inibições, dos tabus e das crenças negativas às quais ainda continua entrelaçada. $E$ em se falando de crenças, por meio da análise dos resultados, notou-se em 
parte dos estudantes a disseminação de um discurso social que, de certo modo, responde com a negação, minimização, tolerância e legitimação do abuso sexual, dificultando a devida atenção que se deve às vítimas, e interferindo também no desencadeamento de crenças subjacentes e condutas de violência (Pereira et al., 2019).

Contudo, convém destacar que o objetivo proposto foi alcançado quando se vislumbrou que a grande maioria discordou das afirmativas (pautadas em crenças que toleram, legitimam e culpabilizam a vítima de abuso) contidas na ECAS. Isto é, mais de 70\% dos participantes não concordaram com esse tipo de crenças, demonstrando possuírem outro tipo de entendimento sobre o fenômeno em questão.

No tocante à autoindicação desse bullying específico, em que cada estudante afirmou se, em algum momento, foi provocador e/ou provocado, constatou-se que o sexo feminino se sobressaiu nos dois papéis. Acredita-se, por conseguinte, que em parte da justificativa para isso está o fato de que o número de participantes do sexo feminino foi superior em relação ao masculino. Ainda neste sentido, outra questão científica foi levantada, isto é, já que as garotas, através de suas autoindicações, se sobressaíram como autoras desse tipo de bullying, então, se faz necessário saber qual é o seu público-alvo e suas especificidades?

Apesar da grande maioria discordar com as afirmativas da ECAS; porém, ao analisar quem é a minoria que optou em manifestar concordância, percebeu-se que são os provocados aqueles que expuseram, através da escala, crenças que toleram/legitimam o abuso sexual. E diante desse dado, acredita-se que estes adolescentes ao serem expostos diariamente a esse tipo de bullying, provavelmente, adentraram num processo de habituação (APA, 2010), e por conta disso, tenderam a tolerar esse tipo de violência, assumindo crenças de que só é considerado abuso sexual quando há violência física grave, a exemplo, do estupro.

Considera-se pontos limitantes desse estudo: o fato de a amostra não ter sido dividida em $50 \%$ de participantes de cada sexo, o que não foi empecilho para se atingir os objetivos propostos. No entanto, não possibilitou a visão equitativa das crenças e dos comportamentos entre os participantes de ambos os sexos; bem como o fato de que não foram realizadas entrevistas qualitativas com os mesmos, a fim de ouvi-los livremente acerca dos fenômenos abuso sexual e bullying, que, de igual modo, não inviabilizou a análise/compreensão dos dados coletados de modo objetivo.

Em vista disso, sugere-se que novas pesquisas sejam implementadas, principalmente, de delineamento qualitativo entre as participantes do sexo feminino, a fim de vislumbrar de modo mais amplo quais são os condicionantes psicossociais e como contribuem para este elevado índice de garotas sendo alvo desse tipo de bullying e, em especial, como autoras.

Portanto, através do presente estudo foi possível observar que as crenças que se tem sobre determinado fenômeno, pode interferir na autoindicação do mesmo. Em outras palavras, as crenças que foram desenvolvidas subjetivamente a partir das vivências objetivas na relação com o mundo/outro (Beck, 1976), que neste caso, estarem expostos, diuturnamente, a episódios de violência escolar, foram a base para a interpretação de que ser acariciado sem ter concedido a permissão não é considerado alvo grave, tal como um bullying do tipo abuso sexual.

\section{Contribuições dos autores}

Felizmino TO atuou desde o planejamento da pesquisa, na coleta dos dados, bem como nas análises e na redação do artigo. Silva JP orientou o trabalho, apoiou no planejamento do estudo, orientou a coleta dos dados, bem como apoiou na análise e redação do artigo.

\section{Conflitos de interesses}

Nenhum conflito financeiro, legal ou político envolvendo terceiros (governo, empresas e fundações privadas, etc.) foi declarado para nenhum aspecto do trabalho submetido (incluindo, mas não se limitando a subvenções e financiamentos, participação em conselho consultivo, desenho de estudo, preparação de manuscrito, análise estatística, etc.).

\section{Referências}

Associação Brasileira Multiprofissional de Proteção à Infância e Adolescência. (1997). Abuso sexual: mitos e realidade. Autores \& Agentes \& Associados. https://andi.org.br/ documento/abuso-sexual-mitos-e-realidades-por-quequem-como-o-que-cartilhal 
Accorssi, A., Scarparo, H., \& Guareschi, P. (2012). A naturalização da pobreza: reflexões sobre a formação do pensamento social. Psicologia \& Sociedade, 24(3), 536-46. https://doi. org/10.1590/S0102-71822012000300007

Almeida, A. C. E. P. (2003). Abuso sexual de crianças: crenças sociais e discursos da psicologia [Dissertação de mestrado, Universidade do Minho]. Repositório da Universidade do Minho. https://repositorium.sdum.uminho.pt/ handle/1822/3197

Alves, R. E. O., \& Leal, L. V. M. (2012). Violência psicológica e a saúde da mulher. Revista Jurídica Eletrônica, 1(6). https:// www.unirv.edu.br/imgs/13\%20VIOL\%c3\%8aNCIA\%20 PSICOL\%C3\%93GICA\%20E\%20A\%20SA\%c3\%9aDE\%20 DA\%20MULHER\%20ED.pdf

Antunes, D. C., \& Zuin, A. A. (2008). Do bullying ao preconceito: os desafios da barbárie à educação. Psicologia \& Sociedade, 20(1), 33-41. https://doi.org/10.1590/S010271822008000100004

American Psychological Association. (2010). Dicionário de Psicologia da APA. Artmed.

Beck, A. T. (1976). Cognitive therapy and the emotional disorders. Penguin.

Bland, J. M., \& Altman, D. G. (1997). Statistics notes: Cronbach's alpha. British Medical Journal, 314(7080), 572. https://doi. org/10.1136/bmj.314.7080.572

Brino, R. F., \& Williams, L. C. A. (2009). A escola como agente de prevenção do abuso sexual infantil. Suprema.

Broussard, S., Wagner, W.G., \& Kazelskis, R. (1991). Undergraduate students' perceptions of child sexual abuse: The impact of victim sex, perpetrator sex, respondent sex, and victim response [As percepções dos estudantes de graduação sobre o abuso sexual infantil: O impacto do sexo da vítima, sexo do perpetrador, sexo do respondente e resposta da vítima]. Journal of Family Violence, 6(3), 267-78. https://doi.org/10.1007/BF00980533

Camino, L., Torres, A. R. R., Lima, M. E. O., \& Pereira, M. E. (2013). Psicologia Social: Temas e Teorias ( $2^{\mathrm{a}}$ ed). Technopolitik. https://en.1 lib.limited/book/5541173/84abb0

Costa, L. F., Junqueira, E. L., Ribeiro, A., \& Meneses, F. F. F. (2011). "Ministério da Obrigação adverte": é preciso proteger os adolescentes ofensores sexuais. Avances en Psicologia Latinoamericana, 29(1), 33-46. http://www.scielo.org.co/ pdf/apl/v29n1/v29n1a04.pdf

De Antoni, C., \& Koller, S. H. (2002). Violência doméstica e comunitária. In Contini, M. L. J., Koller, S. H., \& Barros, M. N. S. (Eds.), Adolescência \& psicologia: concepções, práticas e reflexões críticas (pp.85-91). Conselho Federal de Psicologia. https://site.cfp.org.br/wp-content/ uploads/2008/01/adolescencia1.pdf
Denov, M. S. (2003). To a safer place? Victims of sexual abuse by females and their disclosures to professionals [Para um lugar mais seguro? Vítimas de abuso sexual por mulheres e suas revelações a profissionais]. Child Abuse \& Neglect, 27(1), 47-61. https://doi.org/10.1016/S01452134(02)00509-4

Duarte, G. (2015). Dicionário de administração. KBR

Espelage, L. D., Low, S. K., Anderson, C., \& Ru, L. (2014). Bullying, sexual, and dating violence trajectories from early to late adolescence [Trajetórias de bullying, violência sexual e namoro desde o início até o final da adolescência]. U.S. Department of Justice, National Institute of Justice. https:// www.ojp.gov/pdffiles1/nij/grants/246830.pdf

Facuri, C. O., Fernandes, A. M. S., Oliveira, K. D., Andrade, T. S., \& Azevedo, R. C. S. (2013). Violência sexual: estudo descritivo sobre as vítimas e o atendimento em um serviço universitário de referência no Estado de São Paulo, Brasil. Cadernos de Saúde Pública, 29(5), 889-898. https://doi. org/10.1590/S0102-311X2013000500008

Faleiros, E. T. S. (2000). Repensando os conceitos de violência, abuso e exploração sexual de crianças e de adolescentes. Thesaurus.

Ferenczi, S. (2011). Confusão de Língua entre os Adultos e a Criança (A linguagem da ternura e da paixão). Revista de Psicanálise da Sociedade Psicanalítica de Porto Alegre, 13(1), 13-24. https://revista.sppa.org.br/RPdaSPPA/article/ view/563

Florentino, B. R. B. (2015). As possíveis consequências do abuso sexual praticado contra crianças e adolescentes. Fractal: Revista de Psicologia, 27(2), 139-44. https://doi. org/10.1590/1984-0292/805

Fonseca, T., Portela, A. V. M., Freire, S. E. A., \& Negreiros, F. (2018). Assédio Sexual no Trabalho: Uma Revisão Sistemática de Literatura. Ciências Psicológicas, 12(1), 25-34. http://dx.doi. org/10.22235/cp.v12i1.1592

Fontes, L. F. C., Conceição, O. C., \& Machado, S. (2017). Violência sexual na adolescência, perfil da vítima e impactos sobre a saúde mental. Ciência \& Saúde Coletiva, 22(9), 2919-2928. https://doi.org/10.1590/1413-81232017229.11042017

Gabel, M. (2007). Les enfants victime d'abus sexual [As crianças que são vítimas de abusos sexuais]. Psychiatrie de L'Efant.

Guedes, A., Bott, S., Garcia-Moreno, C., \& Colombini, M. (2016). Bridging the gaps: a global review of inter sections of violence against women and violence against children [Preenchendo as lacunas: uma revisão global das interseções de violência contra as mulheres e de violência contra as criançaS]. Glob Health Action, 9(1), 31516. https:// doi.org/10.3402/gha.v9.31516 
Habigzang, L. F., \& Caminha, R. M. (2004). Abuso sexual contra crianças e adolescentes: Conceituação e intervenção clínica. Casa do Psicólogo.

Hein, V., Koka, A., \& Hagger, M. S. (2015). Relationships between perceived teachers' controlling behaviour, psychological need thwarting, anger and bullying behaviour in high-school students [Relações entre a percepção do comportamento de controle dos professores, a necessidade psicológica de frustrar, a raiva e o bullying nos alunos do ensino médio]. Journal of adolescence, 42, 103-14. https://doi.org/10.1016/j.adolescence.2015.04.003

Hetherton, J. (1999). The idealization of women: Its role in the minimization of child sexual abuse by females [A idealização da mulher: Seu papel na minimização do abuso sexual infantil por parte das mulheres]. Child Abuse \& Neglect, 23(2), 161-74. https://doi.org/10.1016/S01452134(98)00119-7

Ladeiro, C. (2014). Percepção e valoração do diagnóstico de abuso sexual em crianças e adolescentes pelos profissionais de enfermagem [Dissertação de Mestrado, Universidade do Porto]. Repositório Aberto da Universidade do Porto. https://repositorio-aberto.up.pt/handle/10216/77713

Landini, T. S. (2011). O Professor diante da violência Sexual. Cortez.

Machado, C., Gonçalves, R., \& Matos, M. (2000). Escalas para avaliação do enquadramento cultural da violência contra mulheres e crianças. Braga: Universidade do Minho.

Maciel, S. C., Pereira, C. R., Lima, T. J. S., \& Souza, L. E. C. (2015). Desenvolvimento e Validação da Escala de Crenças sobre a Doença Mental. Psicologia: Reflexão e Crítica, 28(3), 46373. https://doi.org/10.1590/1678-7153.201528305

Malta, D. C., Antunes, J. T., Prado, R. R., Assunção, A. A., \& Freitas, M. I. (2019). Fatores associados aos episódios de agressão familiar entre adolescentes, resultados da Pesquisa Nacional de Saúde do Escolar (PeNSE). Ciência \& Saúde Coletiva, 24(4), 1287-298. https://doi.org/10.1590/1413$\underline{81232018244.15552017}$

Marra, M. M., \& Costa, L. F. (2018). Entre a revelação e o atendimento: família e abuso sexual. Avances en Psicología Latinoamericana, 36(3), 459-75. http://dx.doi.org/10.12804/ revistas.urosario.edu.co/apl/a.3564

Matos, K. J. N., Pinto, F. J. M., \& Stelko-Pereira, A. C. (2018). Violência sexual na infância associa-se a qualidade de vida inferior em universitários. Jornal Brasileiro de Psiquiatria, 67(1), 10-7. https://doi.org/10.1590/0047-2085000000178

Mendes, A. P. N., \& França, C. P. (2012). Contribuições de Sándor Ferenczi para a compreensão dos efeitos psíquicos da violência sexual. Psicologia em Estudo, 17(1), 121-30. https://www.scielo.br/j/pe/a/TTvX3yxH39TJV7yMqyHnTtR/ abstract/?lang=pt
Ministério do Trabalho e Emprego. (2013). Assédio moral e sexual no trabalho. Assessoria de Comunicação (ASCOM). https:// siabi.trt4.jus.br/biblioteca/direito/legislacao/norma\%20 sem\%20numero/Cartilha\%20MTE\%20assedio\%20 moral\%20e\%20sexual.pdf

Moyano, N., Monge, F. S., \& Sierra, J. C. (2017). Predictors of sexual aggression in adolescents: Gender dominance vs. rape supportive attitudes [Preditores de agressão sexual em adolescentes: Dominância de gênero vs. atitudes de apoio ao estupro]. The European Journal of Psychology Applied to Legal Context, 9(1), 25-31. https://doi.org/10.1016/j. ejpal.2016.06.001

Pereira, C. A., Maciel, S. C., Dias, C. C. V., Alexandre, T. M. O., Oliveira, M. X., \& Pimentel, C. E. (2019). Validação da Escala de Crenças sobre Abuso Sexual (ECAS) no Contexto Brasileiro. Psico-USF, 24(1), 145-58. https://doi. org/10.1590/1413-82712019240112

Pfeiffer, L., \& Salvagni, E. P. (2005). Visão atual do abuso sexual na infância e adolescência. Jornal de Pediatria, 81(S5), 197-204. https://doi.org/10.1590/S0021-75572005000700010

Platt, V. B., Back, I. C., Hauschild, D. B., \& Guedert, J. M. (2018). Violência sexual contra crianças: autores, vítimas e consequências. Ciência \& Saúde Coletiva, 23(4), 1019-31. https://doi.org/10.1590/1413-81232018234.11362016

Pincolini, A. M. F., \& Hutz, C. S. (2014). Abusadores sexuais adultos e adolescentes no sul do Brasil: pesquisa em denúncias e sentenças judiciais. Temas em Psicologia, 22(2), 301-312. http://dx.doi.org/10.9788/TP2014.2-03

Roth, G., Kanat-Maymon, Y., \& Bibi, U. (2011). Prevention of school bullying: The important role of autonomy-supportive teaching and internalization of pro-social values [Prevenção do bullying escolar: O importante papel da autonomia - apoio ao ensino e internalização dos valores pró-sociais]. British Journal of Educational Psychology, 81(4), 654-66. https://doi.org/10.1348/2044-8279.002003

Salgado, F. S. (2012). Crenças de gestores escolares em relação ao bullying [Dissertação de mestrado, Universidade Federal de Juiz de Fora]. Repositório Institucional da Universidade de Juiz de Fora. https://repositorio.ufjf.br/jspui/handle/ ufjf/5696

Salmivalli, C., Kärnä, A., \& Poskiparta, E. (2011). Counteracting bullying in Finland: The KiVa program and its effects on different form sofbeing bullied [Contra-atacar o bullying na Finlândia: O programa KiVa e seus efeitos em diferentes formas de intimidação de sofás]. International Journal of Behavioral Development, 35(5), 405-11. https:// doi.org/10.1177/0165025411407457

Sanderson, C. (2005). Abuso sexual em crianças: Fortalecendo pais e professores para proteger crianças contra abuso sexual e pedofilia. M Books do Brasil. 
Santos, M. J., Mascarenhas, M. D. M., Rodrigues, M. T. P., \& Monteiro, R. A. (2018). Caracterização da violência sexual contra crianças e adolescentes na escola - Brasil, 20102014. Epidemiologia e Serviços de Saúde, 27(2), e2017059. https://doi.org/10.5123/S1679-49742018000200010

Santos, S. S., \& Dell'Aglio, D. D. (2008). Compreendendo as mães de crianças vítimas de abuso sexual: ciclos de violência. Estudos de Psicologia (Campinas), 25(4), 595-606. https:// www.lume.ufrgs.br/handle/10183/98576

Serafim, A. P., Saffi, F., Rigonatti, S. P., Casoy, I., \& Barros, D. M. (2009). Perfil psicológico e comportamental de agressores sexuais de crianças. Archives of Clinical Psychiatry, 36(3), 101-11. https://doi.org/10.1590/S0101$\underline{60832009000300004}$

Silva, A. A., \& Inada, J. F. (2013). As implicações psicológicas e comportamentais do abuso sexual infantil. Encontro Internacional de Produção Científica. http://rdu.unicesumar. edu.br/handle/123456789/4266

Silva, R. A., \& Teixeira, L. C. (2017). Adolescência e o traumático: sobre abuso sexual e as vicissitudes do sujeito. Revista Subjetividades, 17(3), 92-103. http://dx.doi. org/10.5020/23590777.rs.v17i3.6955

Tsukamoto, S. A. S., Galdino, M. J. Q., Robazz, M, L. C. C., Ribeiro, R. P., Soares, M. H., Haddad, M. C. F. L., \& Martins, J. T. (2019). Violência ocupacional na equipe de enfermagem: prevalência e fatores associados. Acta Paulista de Enfermagem, 32(4), 425-432. https://doi.org/10.1590/1982$\underline{0194201900058}$
United Nations Children's Fund. (2006). Behind closed doors: The impact of domestic violence on children [Atrás de portas fechadas: O impacto da violência doméstica sobre as crianças]. Unicef. https://www.acesdv.org/wp-content/ uploads/2014/06/BehindClosedDoors.pdf

Viana, N. (2013). Naturalização e desnaturalização: o dilema da negação prático-crítica. Revista Espaço Livre, 8(3), 71-80. http://redelp.net/revistas/index.php/rel/article/view/210

Wolff, L. S., Amparo, D. M., Oliveira, R. M., \& Chagnon, J. Y. (2016). Problemática narcísica-identitária em adolescentes abusadores sexuais: contribuições do Rorschach Escola de Paris. Avaliação Psicológica, 15(3), 318-26. http://dx.doi. org/10.15689/ap.2016.1503.04

World Health Organization. (2006). Preventing child maltreatment: a guide to taking action and generating evidence [Prevenção de maus-tratos a crianças: um guia para agir e gerar evidências]. International Society for Prevention of Child Abuse and Neglect. https://www.who.int/publicationsdetail-redirect/preventing-child-maltreatment-a-guide-totaking-action-and-generating-evidence 